\title{
Tech-based Social Enterprises in Healthcare
}

\author{
Nurfarini Daing Abdul Rahman \\ MyHarapan \\ Damansara Intan, Petaling Jaya, Selangor
}

\begin{abstract}
Disruptive technologies continue to redefine how we live, far faster than we could have ever imagined. Technologies from Artificial Intelligence to IoT, are powering solutions in the healthcare sector and paving the way to incredible new medical "miracles". The question now is, how can we ensure that these technologies deliver quality care that is accessible to the people who need it the most, effectively and sustainably- the poor in urban or remote areas, the marginalized and underserved who are not able to benefit from it? This issue is compounded by the complexities of the social determinants of health, which cuts across the layers of our existence in this increasingly fast-paced, volatile and uncertain world. New models to delivering healthcare products and services have been embraced by a relatively new breed of entrepreneurs, the kind driven by a social mission. Together with healthcare practitioners, experts and institutions, and most importantly, patients (or preferably consumers), Social Business Entrepreneurs are challenging the norm through technological applications and savvy business models and reimagining how our world could be. Will we, in the future, no longer have a need for human doctors? How can wellness be afforded to even the very poor? Referencing several notable Healthcare Social businesses in the industry, the presentation hopes to provide a starting point to deeper discussions - a call to action for all participants- into a sector that requires multi-stakeholder participation and support in order to move the needle even further.
\end{abstract}

